\title{
A Review: Biological and Clinical Aspects of Pyrimidine Metabolism
}

\author{
RODNEY L. LEVINE, NICHOLAS J. HOOGENRAAD, \\ AND NORMAN KRETCHMER(165) \\ Division of Developmental Biology, Department of Pediatrics, Stanford University \\ Medial Center, Stanford, California, USA
}

Interest in pyrimidine nucleotide biosynthesis has stemmed largely from the importance of these molecules as components of nucleic acids. Regulation of pyrimidine biosynthesis has been most extensively investigated in micro-organisms in which cell division is effectively controlled by regulation of the activity of the enzymes of the de novo pathway $(77,110)$ The relation between pyrimidine biosynthesis and cellular proliferation in mammals has become clearer with the accumulation of a considerable body of evidence which indicates that there is a close correlation between the activity of enzymes involved in pyrimidine biosynthesis and the rate of cellular proliferation.

The de novo pyrimidine biosynthetic pathway and the urea cycle both utilize carbamyl phosphate, and important nitrogen carrier. The biosynthesis of pyrimidine and purine nucleotides are connected by a common intermediate, phosphoribosyl pyrophosphate (PRPP). In addition, pyrimidine nucleotides act as sugar and phospholipid carriers and are important in lipopolysaccharide biosynthesis. The importance of these interrelations is most forcibly emphasized by certain clinical phenomena which will be discussed later.

This paper will attempt to review the broad biologic aspects of pyrimidine nucleotide biosynthesis. A detailed consideration of de novo pyrimidine biosynthesis in eucaryotic cells is available in the recent review by Jones (81). Pyrimidine biosynthesis in procaryotes has been reviewed in depth by O'Donovan and Neuhard (110).

\section{PATHWAYS OF PYRIMIDINE NUCLEOTIDE BIOSYNTHESIS}

In cells from multicellular organisms, pyrimidine nucleotide biosynthesis can proceed by two mechanisms. De novo biosynthesis of uridylic acid proceeds from simple components such as carbon dioxide, a source of nitrogen (either ammonia or the amide nitrogen of glutamine), ATP, aspartate, and ribose in the form of phosphoribosyl pyrophosphate. A reutilization ("salvage") mechanism is also available to cells, whereby preformed pyrimidine bases or nucleosides can be converted to the nucleotide by the addition of ribose phosphate or phosphate.

\section{DE NOVO MECHANISM}

De novo biosynthesis of uridylic acid required six enzymatic steps (Fig. 1). In procaryotes one enzyme supplies the carbamyl phosphate required for both pyrimidine nucleotide and arginine biosynthesis. Consequently, aspartate transcarbamylase is the first enzyme unique to the de novo pyrimidine pathway and an important locus for control of the pathway (77).

In contrast, in ureotelic vertebrates, there are two carbamyl phosphate synthetases. The first, carbamyl phosphate synthetase I, is located in the inner membrane of the mitochondrion of the liver and also appears to be present in small quantities in kidney and small intestine (82). The second, carbamyl phosphate synthetase II, has a more ubiquitous distribution and was first demonstrated to be present in Ehrlich ascites cells $(58,59)$ and in hematopoietic mouse spleen $(75,143)$. This enzyme was originally difficult to detect because of its relatively low activity and high lability. However, the discovery that the enzyme could be stabilized by its substrate, magnesium-ATP (59), and by dimethyl sulfoxide and glycerol $(144,146)$, made it possible to demonstrate that the enzyme was widely distributed in mammalian tissues $(74,128,144$, 163).

The two synthetases have different properties which lends support to the concept that they have distinct roles in supplying carbamyl phosphate for either arginine biosynthesis

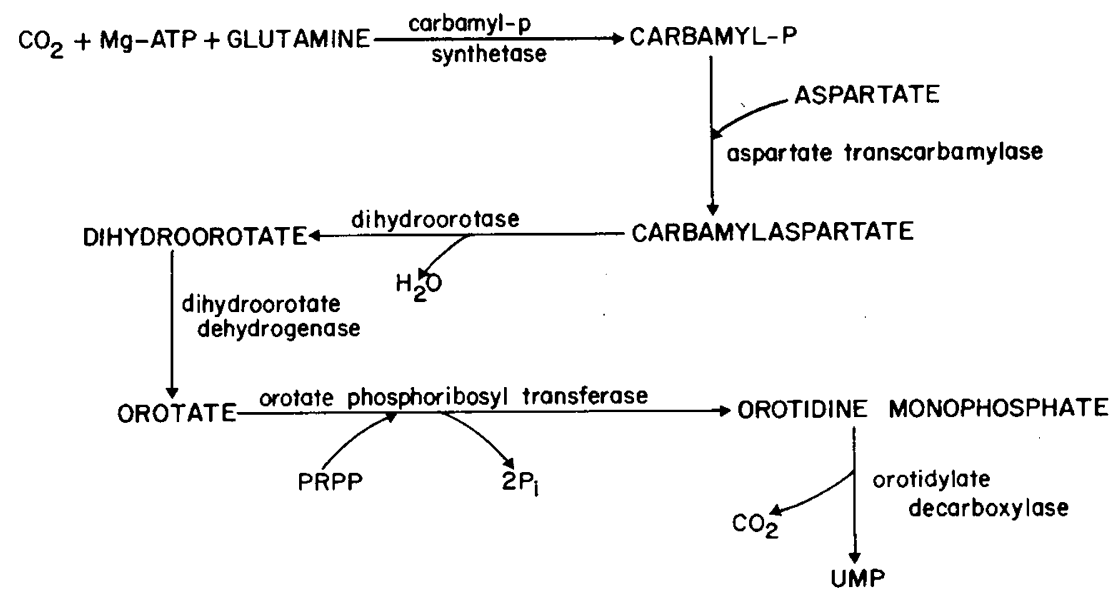

Fig. 1. Pathway for de novo biosynthesis of pyrimidine nucleotides in eucaryotic cells. PRPP: phosphoribosyl pyrophosphate. 
or for uridylic acid biosynthesis (80). The mitochondrial carbamyl phosphate synthetase I can utilize ammonia as a source of nitrogen and is activated by $N$-acetyl glutamate, which also stimulates urea biosynthesis in liver slices. Carbamyl phosphate synthetase II, found in the cytosol, utilizes glutamine as its normal nitrogen source as indicated by the $\mathrm{K}_{\mathrm{m}}$ values for glutamine and ammonia (144). In addition, glutamine analogs inhibit this enzyme but do not affect carbamyl phosphate synthetase I $(59,60,163)$. The role of carbamyl phosphate synthetase II in de novo pyrimidine biosynthesis is indicated, not only by its general distribution in most tissues, but also by the factors that control its activity. $\mathrm{UTP}$, an end product of the de novo pyrimidine pathway, is a feedback inhibitor of carbamyl phosphate synthetase II (74, 94, 143), apparently acting in an allosteric fashion (94). Phosphoribosyl pyrophosphate, a substrate required for both purine and pyrimidine biosynthesis, enhances the activity of carbamyl phosphate synthetase II when added at low concentrations $(132,145,147)$.

The second enzyme of the do novo pathway is aspartate transcarbamylase (EC. 2.1.3.2). In fungi this enzyme is part of a multifunctional complex which also contains carbamyl phosphate synthetase II (81). These two enzymes are also in close physical association in mammalian tissues $(71,80)$. In addition, Shoaf and Jones (130-132) found that the third enzyme of the de novo pyrimidine pathway, dihydroorotase (EC. 3.5.2.3), is also present in the complex.

The aspartate transcarbamylase activity of the mammalian complex, unlike the enzyme from many procaryotic species and yeast, is not sensitive to feedback regulation by nucleotides $(35,71,120)$.

Dihydro-orotase activity is only marginally affected by pyrimidine compounds, with the exception of orotic acid, which substantially inhibits the enzyme $(19,58)$. Dihydroorotic acid dehydrogenase (EC. 1.3.3.1), the next enzyme in the pathway, is possibly the least studied of the de novo pyrimidine enzymes. The electron acceptor for the conversion of dihydro-orotic acid to orotic acid has not been characterized for the mammalian enzyme. This enzyme is apparently associated with the cell membranes since Shoaf and Jones (132) showed that, in contrast to the other enzymes required for de novo pyrimidine nucleotide biosynthesis, the majority of the dihydro-orotate dehydrogenase activity from Ehrlich ascites cells sediments with the nuclei and cell membrane fraction.

The terminal two enzymes of the de novo pyrimidine pathway also exist as a complex in mammals. Appel (2) found that orotate phosphoribosyl transferase and orotidylate decarboxylase copurified when these enzymes were isolated from bovine brain. The two enzymes have also been copurified from thymus gland and erythrocytes $(63,83)$ and they cosediment in a sucrose gradient when extracted from Ehrlich ascites cells $(131,132)$. The complex from thymus gland can be separated on starch gel, but when separated, the transferase activity may be completely lost (83).

Genetic evidence from humans with congenital orotic aciduria is consistent with the concept that orotate phosphoribosyl transferase and orotidylate decarboxylase form as enzyme complex. In all but one of the cases reported, only very low levels of both of the enzymes were detected $(12,136)$.

The one exception was the case described by Fox et al. (47), in which a very low orotidylate decarboxylase level was accompanied by an elevated orotate phosphoribosyl transferase.

The presumed advantage to the cell of enzyme complexes in the de novo pathway lies in the physical separation of pyrimidine and arginine-urea biosynthesis. It has been shown that, in Neurospora, the complex existing between carbamyl phosphate synthetase II and aspartate transcarbamylase enables the carbamyl phosphate synthesized in the cytoplasm to be effectively channeled into de novo pyrimidine biosynthesis $(36,80)$.

It has become evident recently that the conversion of orotate to uridylate may be an important site of regulation in de novo pyrimidine biosynthesis. Uridine substantially inhibits the incorporation of $\left({ }^{14} \mathrm{C}\right)$ aspartate $(117)$ and ${ }^{14} \mathrm{CO}_{2}(70)$ into uridine nucleotides in hepatoma cells. Hoogenraad and Lee (70) showed that the effects of uridine were caused by an effect on the level of activity of orotate phosphoribosyl transferase, even though uridine or its nucleotides did not directly inhibit this enzyme. In addition, it appears that the availability of PRPP may be crucial in the regulation of de novo pyrimidine biosynthesis, inasmuch as orotate accumulates in cultures of mammalian cells to which small amounts of adenine have been added (73), and the toxic effects of adenine $(73,102)$ may be removed by supplementation of cells with uridine (73), showing that the toxicity is caused by pyrimidine starvation.

The activity of orotidylate decarboxylase also can be regulated by the pyrimidine nucleotides, UMP and CMP $(3,15$, $16,33)$. However, it is doubtful that this is an important regulatory mechanism, because the $\mathrm{K}_{\mathrm{i}}$ for inhibition by these nucleotides is high and the levels of UMP and CMP are usually extremely low $(3,117)$.

\section{REUTILIZATION OF PYRIMIDINE NUCLEOSIDES}

Pyrimidine nucleosides from exogenous sources and from endogenous breakdown of nucleic acids are available for pyrimidine nucleotide biosynthesis through the mediation of a number of enzymes which have collectively been called the "salvage pathway" or "reutilization pathway." The enzymes of this pathway (Fig. 2) found in mammalian tissues are uridine phosphorylase (EC. 2.4.2.3), uridine kinase (EC. 2.7.1.48), and thymidine kinase (EC. 2.4.2.4).

Uridine phosphorylase catalyzes reversibly the reaction between uracil and ribose 1-phosphate to form uridine and inorganic phosphate. The enzyme is widely distributed in animal tissues $(23,86)$. Uridine kinase catalyzes the conversion of uridine to UMP. The name is somewhat limiting because the enzyme will also convert cytidine to CMP (134). Uridine kinase is required for the conversion of the antineoplastic agent 5-fluorouracil to the active nucleotide, and resistance to this drug occurs when the enzyme becomes modified (135). In the sequence of reactions leading from uridine to UTP, the conversion of uridine to UMP is rate limiting and sensitive to inhibition by UTP and CTP (1). The phosphorylation of cytidine is also inhibited by UTP and CTP.

Thymidine kinase is also widely distributed in animal tissues as evidenced by the widespread use of radioactively labeled thymidine to measure DNA biosynthesis. As is the case with uridine kinase (90), thymidine kinase appears to be present in fetal and adult liver in different forms $(22,87)$, and its activity is subject to product inhibition by dTTP and dCTP (22).

\section{INTERCONVERSIONS OF PYRIMIDINE NUCLEOTIDES}

Uridylic acid is converted into the range of pyrimidine nucleotides required for mammalian metabolism by a series of enzymes, many of which appear to be under complex

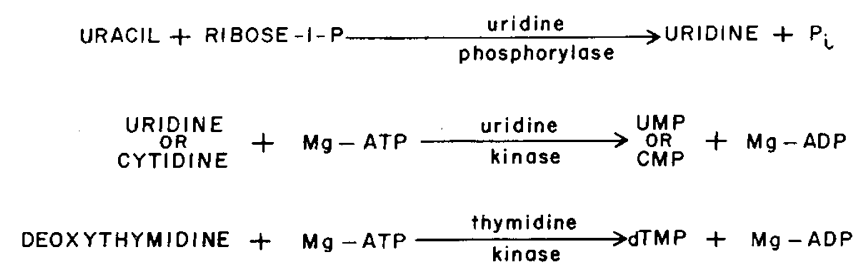

Fig. 2. Reutilization pathway for the conversion of preformed pyrimidine nucleosides into nucleotides. 
metabolic control. These enzymes have been extensively studied in micro-organisms $(23,110)$, and research with the mammalian enzymes indicates that many of the controls are similar to those found in micro-organisms $(86,137)$. Figure 3 summarizes the reactions involved in the interconversions of pyrimidine nucleotides.

PYRIMIDINE NUCLEOTIDES IN CARBOHYDRATE AND LIPID BIOSYNTHESIS

The importance of pyrimidine nucleotides in carbohydrate metabolism is exemplified by the role of UDP-glucose as a substrate for glycogen synthetase (68) and of UDP-galactose as a substrate for galactose transferase (4). The rapidity with which glucogen pools are turned over and the extent of lactose biosynthesis in lactating mammary glands support the quantitative importance of uridine nucleotides in the cellular metabolism of carbohydrates.

Synthesis of cell membranes also requires pyrimidine nucleotides as carriers of lipopolysaccharide precursors. For example, cytidine nucleotides are required in the de novo biosynthesis of choline, ethanolamine, and inositol glycerolphosphates. The biosynthesis of phosphatides apparently takes place in the endoplasmic reticulum of mammalian cells, whereas the cydidine nucleotides are produced in the cytosol (103), the site of the de novo pyrimidine pathway. Pyrimidine nucleotides are also required in the biosynthesis of glycolipids, glycoproteins, and free polysaccharides which are found on mammalian cell surfaces $(114,161)$.

Although it is clear that pyrimidine nucleotides have widespread functions in cellular metabolism, it is not known whether there are separate controls that regulate the supply of pyrimidine nucleotides for carbohydrate and lipid metabolism. It would seem unlikely that the biosynthesis of pyrimidine nucleotides is regulated solely by cell division, as metabolic processes such as glycogen biosynthesis require that there be a considerable supply of pyrimidine nucleotides even in the absence of cellular division. Interference with this supply of pyrimidine nucleotides can lead to pathologic changes in tissues (see below).

\section{DEGRADATION OF PYRIMIDINES}

Pyrimidines are degraded in the liver primarily to carbon dioxide and $\beta$-alanine. The degradative route for pyrimidine nucleotides proceeds via uracil or thymine. These two pyrimidine bases share a common degradative pathway which utilizes the same enzymes. The degradation of cytosine therefore requires prior deamination to uracil which is accomplished by cytidine aminohydrolase (EC. 3.5.4.5). This enzyme has been found in a number of animal tissues $(26,34$, 148).

In animals degradation of pyrimidine bases proceeds by three enzymatic steps as shown in Figure 4. Dihydrouracil dehydrogenase (EC. 1.3.1.2) has been isolated from liver and

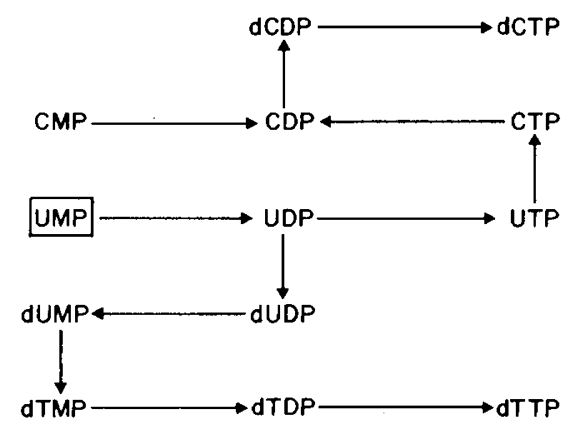

Fig. 3. Reactions involved in the interconversions of pyrimidine nucleotides.

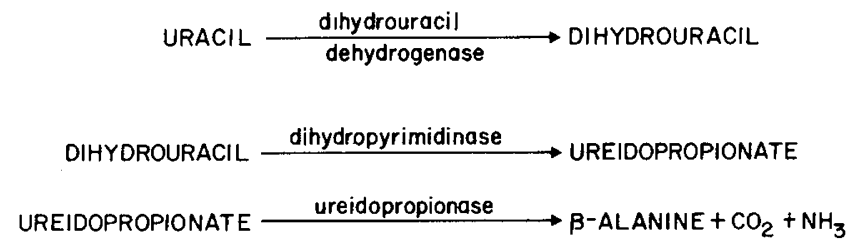

Fig. 4. Pathway for the degradation of uracil into $\beta$-alanine and carbon dioxide. The same enzymes also catalyze the degradation of thymine.

requires NADP for the reduction of uracil or thymine $(56$, 153). This enzyme is rate limiting in the degradative pathway of pyrimidines (27), and its activity is inversely proportional to the growth rate of liver cells and hepatomas (155).

The dihydropyrimidinase (EC. 3.5.2.2) of liver is capable of hydrolyzation of both dihydrouracil and dihydrothymine (153). The carbamyl $\beta$-amino acids formed in this reaction are further degraded to carbon dioxide and ammonia by ureidopropionase (EC. 3.5.1.6), which is specific for the carbamyl $\beta$-amino acids derived from uracil and thymine (28).

The rate of pyrimidine breakdown appears to vary inversely with the rate of growth in mammalian cells. For example, the activities of enzymes in this pathway are low in liver of newborn animals (42) and increase with age, so that the ability of adult liver to degrade pyrimidine bases far exceeds its ability to utilize them for nucleic acid biosynthesis (118). As a result of this degradative capacity, label from tritiated thymidine or deoxycytidine is incorporated into lipid of adult liver more rapidly than into DNA $(119,127)$.

\section{INTERRELATION OF UREA AND PYRIMIDINE PATHWAYS HYPERAMMONEMIA AND OROTIC ACIDURIA}

Carbamyl phosphate is an initial reactant in both urea and de novo pyrimidine biosynthesis. As discussed above, there are two distinct carbamyl phosphate synthetases. The mitochondrial synthetase subserves arginine and urea biosynthesis whereas the nonmitochondrial synthetase provides carbamyl phosphate for pyrimidine biosynthesis $(79,80)$. With the detection of two synthetases there was no basis to assume that urea and pyrimidine biosynthesis were closely linked. However, recent evidence suggests that the two carbamyl phosphate pools are not always completely compartmentalized and that carbamyl phosphate produced in liver mitochondria may become available for utilization in de novo pyrimidine biosynthesis. Natale and Tremblay (107) showed that intact isolated mitochondria from rat liver may release carbamyl phosphate which is presumably available for pyrimidine biosynthesis or other reactions (109).

Hyperammonemia occurs whenever there is a genetic defect in one of the urea cycle enzymes (32). If the enzymatic defect also causes an accumulation of carbamyl phosphate, such as with a deficiency of ornithine transcarbamylase (EC. 2.1.3.3), the patient may excrete orotic acid, uridine, and other pyrimidine-containing compounds (129). Thus, orotic aciduria can occur both in hereditary orotic aciduria (136) because of a block in de novo pyrimidine biosynthesis at the orotate phosphoribosyl transferase and orotidylate decarboxylase steps, and in urea cycle defects with hyperammonemia (55). The excretion of orotic acid in urea cycle defects presumably occurs because mitochondrial carbamyl phosphate which cannot be utilized for urea biosynthesis becomes available for extramitochondrial pyrimidine biosynthesis. Thus, Goldstein et al. (55) found that excretion of orotic acid in urine parallels the blood ammonia concentration in a patient with congenital hyperammonemia due to ornithine transcarbamylase deficiency (Fig. 5).

In the last few years total parenteral nutrition ("hyperali- 


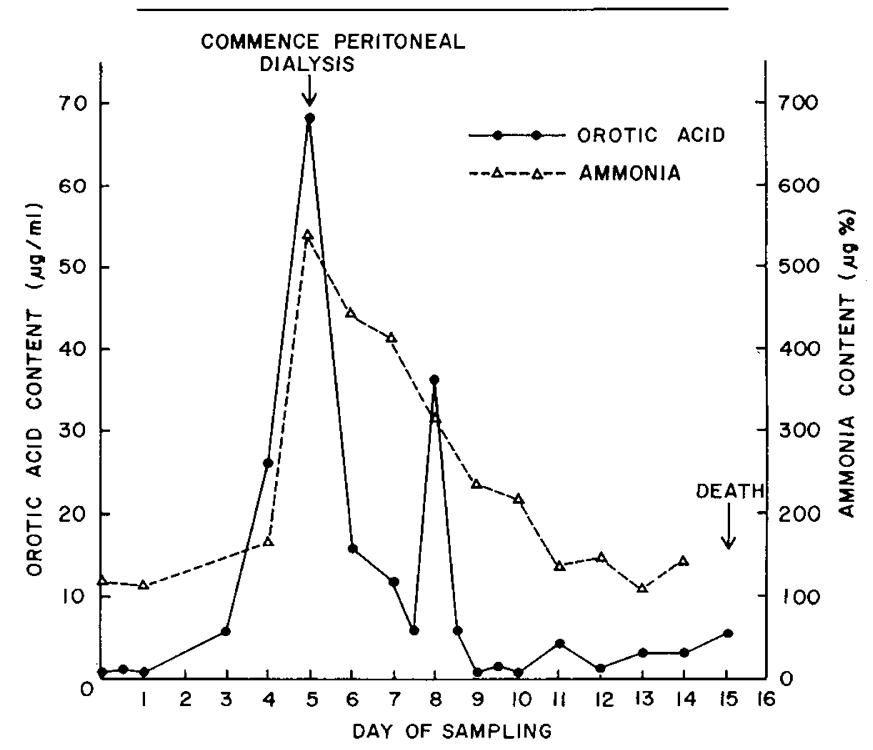

Fig. 5. Correlation of orotic acid in urine and ammonia in plasma in a male infant with a deficiency of ornithine transcarbamylase. This figure is reproduced from Goldstein et al. (55) with permission of the authors and publisher.

mentation") has been introduced as a means of supplying all the nutritional requirements of patients. This method of feeding is widely used with infants, but it was shown that hyperammonemia may be a complication of total parenteral nutrition (78). Amino acids are usually supplied by a solution of casein or fibrin hydrolysate which may contain $36,000 \mu \mathrm{g}$ ammonia in each $100 \mathrm{ml}$ solution. This concentration of ammonia would give rise to only $100 \mathrm{mg} / \mathrm{kg} / 24 \mathrm{hr}$ of urea, an amount which even a premature infant should be able to synthesize $(78,108)$. Furthermore, Heird and associates (66) have reported hyperammonemia in infants receiving total parenteral nutrition from a synthetic solution of amino acids in which the ammonia content was negligible. It may be, therefore, that hyperammonemia associated with total parenteral nutrition is secondary to a metabolic imbalance which inhibits urea biosynthesis.

The site of the potential metabolic block in the urea cycle is not known, but we have found the orotic acid content of urine from infants on total parenteral nutrition was usually elevated during periods of hyperammonemia. The presence of orotic aciduria suggests that there is a block in urea biosynthesis at the ornithine transcarbamylase step. It seems likely that the enzyme is intact in such patients, so the block is presumed to be caused either by the presence of an inhibitor of the enzyme or by a deficiency of ornithine, a substrate of the enzyme.

In support of the latter suggestion, it has recently been reported that growing rats fed a diet low in arginine developed hyperammonemia and had orotic aciduria because of a lowered availability of ornithine for urea biosynthesis (105). In addition, Heird et al. (66) have reported that the infusion of additional arginine relieves rapidly the hyperammonemia associated with total parenteral nutrition.

\section{DE NOVO VERSUS REUTILIZATION PATHWAYS: POSSIBLE ROLE OF LIVER}

The nucleotide requirements of different tissues may be supplied by de novo pyrimidine and purine biosynthesis or by utilization of preformed nucleosides carried in the blood stream. Murray (106) has recently reviewed evidence supporting the hypothesis that the liver is the major source of preformed purine nucleosides. These nucleosides, synthesized de novo in the liver, are transported by the circulation for utilization by other organs via the reutilization pathway.

Evidence for this key role of the liver as an exporter of purines is accumulating, but investigations on pyrimidine export are limited. Nevertheless, available evidence indicates that the liver synthesizes pyrimidine nucleosides de novo for export to peripheral tissues. Nonhepatic tissues can incorporate blood-borne nucleosides via the reutilization pathway, although they may also synthesize pyrimidine nucleotides de novo. As mentioned previously, de novo pyrimidine biosynthesis occurs in dividing cells derived from a number of different tissues.

The major techniques employed by investigators to infer whether a given tissue utilized the de novo or reutilization pathway have been the determination of tissue enzyme activities and measurement of the incorporation of labeled precursors into nucleic acids. The difficulty of drawing conclusions from these studies is demonstrated by measurements made with bone marrow. Studies on nucleic acid turnover in rat marrow indicated that $80 \%$ of thymine was incorporated via the reutilization pathway (40). Bone marrow makes a considerable amount of nucleic acid available for reutilization through the extrusion of reticulocyte nuclei (14), and it has been shown that at least $35 \%$ of the thymine liberated by bone marrow is reutilized by the marrow itself (41). In spite of the apparent importance of the reutilization pathway, marrow has relatively high levels of activity of enzymes from the de novo pyrimidine biosynthetic pathway, which has led to the conclusion that this pathway could be quantitatively more important than the reutilization pathway.

Based on their incorporation studies, Hogans et al. (69) concluded that the brain normally utilizes preformed pyrimidine precursors. They isolated surgically all organs below the diaphragm from the circulation, eliminating hepatic participation. Uridine was then found to be far more effective than orotic acid in labeling brain RNA of the rat. In contrast, Michaelis and Mandel (104) followed the incorporation of labeled precursors when injected directly into the cerebrospinal fluid. In this case there was effective labeling by orotic acid as well as uridine. Developmental patterns for enzymes required for pyrimidine nucleotide biosynthesis in rat brain suggest that de novo pyrimidine biosynthesis is important in immature animals, whereas adult brains rely primarily on the reutilization pathway (156).

The clearest indication of the role of the liver in providing pyrimidine nucleosides for the brain comes from a beautiful series of experiments by Geiger (53) and Geiger and Yamasaki (54). Using isolated, perfused cat brain they demonstrated that the presence of cytidine and uridine in the blood is essential for maintaining normal brain functions. Isolated, perfused cat brains show an increasing degree of anaerobic glycolysis, develop lactic acidosis and hypoglycemia, and die within $1 \mathrm{hr}$ of isolation. Insertion of the liver into the circulation corrects the changes in carbohydrate metabolism and allows survival for 2-3 hr. Geiger and Yamasaki (54) showed that inclusion of the liver was unnecessary if small amounts of cytidine and uridine were included in the perfusate. Addition of these nucleosides apparently facilitated the transfer of glucose into the brain, which restored the brain lactic acid and glucose concentrations to normal and allowed survival for $5 \mathrm{hr}$. The following pyrimidine nucleosides appear to be required for lipid metabolism as well. Cytidine prevented or restored the loss of phosphatides, presumably by providing CDP carriers for lipid biosynthesis. Uridine prevented or restored the loss of galactolipids, presumably by providing UDP carriers for sugar biosynthesis. The ability of cytidine and uridine to replace the liver provides evidence implicating the liver in export of pyrimidine nucleosides to the brain.

The growing fetus, with its rapid rate of cellular division, has a great demand for pyrimidine nucleotides. The origin of these nucleotides has not been established, but there is good 
evidence for maternal-fetal transfer of pyrimidine nucleosides. Cytidine and uridine readily traverse the placenta and label fetal nucleic acids $(57,64,65,91)$. Rapid transfer is observed in the rat after the 17 th day of gestation, a time which corresponds to a period of rapid absolute growth when demand for pyrimidines would be high (65). These studies also indicate that uridine may be the nucleoside species exported by the maternal liver. At 19 days of gestation, orotic acid labels maternal liver RNA, but uridine does not; the placenta and fetus are labeled by both precursors (65). There is also a very high incorporation of orotic acid and cytidine into RNA of maternal liver as compared with uridine (Table 1).

Gurpide et al. (57) have shown that about $40-60 \%$ of fetal blood uridine is of maternal origin. The demonstration of high rates of uridine production coupled with the large maternalfetal contribution suggest an important role for blood-borne uridine as a precursor of nucleic acids. Tseng et al. (150) also found a very high rate of irreversible removal of pyrimidine nucleosides from the circulation of dogs and humans, which again implicated the blood supply as an important carrier of nucleosides.

Dietary intake also provides a source of preformed pyrimidines, although they are rapidly catabolized and are not significant sources of nucleosides $(13,118)$. Consequently, humans can be maintained readily on base-free diets. Furthermore, isotope studies in man have demonstrated that there is significant reutilization of the nucleoside uridine, but not of the free base, uracil (157), which suggests that dietary nucleic acids probably account for the postprandial rise in blood uridine noted by Tseng et al. (150).

\section{PYRIMIDINE METABOLISM IN MODELS OF PROLIFERATION AND DIFFERENTIATION}

Pyrimidine nucleotides are involved in a variety of important pathways within the matrix of cellular biochemistry. However, their key role in nucleic acid biosynthesis has led to many studies of the pathway in systems which are characterized by rapid cellular division.

\section{PHYTOHEMAGGLUTININ-STIMULATED HUMAN LYMPHOCYTES}

Lymphocy tes can be stimulated to transform into blast cells in the presence of phytohemagglutinin. The stimulated cells synthesize DNA and then undergo mitosis and cell division. In the lag period preceding DNA biosynthesis there is a stimulated RNA biosynthesis, but there is no increase in activities of many of the enzymes associated with nucleic acid metabolism $(97,122)$. The reutilization pathway enzyme, uridine kinase, is one of the few enzymes with stimulated level of activity reaching a peak $6-10 \mathrm{hr}$ after stimulation with phytohemagglutinin (97). Thymidine kinase activity also is stimulated, reaching a peak at a time when DNA biosynthesis is at a maximum (122). The activities of the de novo pyrimidine pathway enzymes aspartate transcarbamylase, dihydro-orotase, orotate phosphoribosyl transferase, and orotidylate decarboxylase are not affected by the phytohemagglutinin (98). More recently however, Ito and Ichino (76) found

Table 1. Incorporation of labeled nucleosides into RNA of maternal liver compared with concentration in maternal blood

\begin{tabular}{lc}
\hline Nucleoside & $\begin{array}{c}\text { Ratio of concentration, maternal } \\
\text { liver/maternal blood }\end{array}$ \\
\hline Thymidine & 3.4 \\
Uridine & 1.6 \\
Cytidine & 25.4 \\
Orotic Acid & 17.7
\end{tabular}

${ }^{1}$ Data from Hayashi and Garvey (64). that incorporation of radioactive carbon dioxide into the uridine nucleotide pool of lymphocytes was stimulated before RNA biosynthesis began, suggesting an increased activity of the de novo pathway. Further, there was an increase in the activity of the glutamine-requiring carbamyl phosphate synthetase preceding the increased incorporation of labeled carbon dioxide. The increased synthetase activity could be blocked by actinomycin $\mathrm{D}$. This finding is an important one in view of the fact that the activity of carbamyl phosphate synthetase is so low as to limit the rate of de novo pyrimidine biosynthesis in normal lymphocytes. Thus the two- to fourfold stimulation observed in the activity of this enzyme has an important effect on the availability of pyrimidine nucleotides for nucleic acid biosynthesis (76).

Measurement of the incorporation of radioactive precursors into nucleic acids has often been used to study the relation of pyrimidine metabolism to cellular proliferation. The careful studies of Forsdyke $(43,44)$, using phytohemagglutinin-stimulated lymphocytes, have emphasized the difficulties associated with such measurements. Forsdyke found that there were fluctuations in the size of endogenous pyrimidine pools after stimulation with phytohemagglutinin. The extent of dilution of labeled precurosr before incorporation into nucleic acids depended on culture conditions and the time which had elapsed since stimulation. Furthermore, the incorporation of orotic acid into RNA was shown to be dependent upon the size of the endogenous pools of preformed nucleosides present in the lymphocytes and in exogenously added serum. In these experiments there was no stimulation by phytohemagglutinin of incorporation of tritiated uridine and tritiated orotic acid into DNA. Uridine was incorporated readily into RNA, but orotic acid was not, particularly when uridine was also added. The incorporation of orotic acid into RNA may have been inhibited because of the presence of a phosphorylated derivative of uridine or cytidine (43) which could inhibit the conversion of orotate to uridylate (see earlier discussion).

\section{ISOPROTERENOL STIMULATED SALIVARY GLANDS}

A single injection of the sympathomimetic amine, isoproterenol, results in a marked stimulation of DNA biosynthesis in the salivary glands of mice and rats. This is followed by increased mitotic activity and cell division $(5,7,8)$. Twenty to $30 \mathrm{hr}$ elapse between the time of injection and DNA biosynthesis, making this experimental model a suitable one for the study of the events that lead to DNA biosynthesis and cellular division. Many of the phenomena that occur during this lag period have been reviewed by Baserga (9).

Important events occur in the 1 st hr after stimulation which are crucial for subsequent DNA biosynthesis. For example, the stimulated DNA biosynthesis is inhibited by actinomycin D given either $30 \mathrm{~min}$ before or $60 \mathrm{~min}$ after administration of isoproterenol (10). Administration of cycloheximide in the first hours after stimulation likewise blocks the increased DNA biosynthesis (126). Events that occur before DNA biosynthesis include an increased incorporation of radioactively labeled orotic acid and uridine into RNA $(6,10,99,125)$, biosynthesis of acidic nuclear protein (141), and biosynthesis of glycolipid $(38,51)$. In these stimulated salivary glands, as well as in phytohemagglutinin-stimulated lymphocytes (43), there is little or no stimulation of the incorporation of uridine or orotic acid into DNA.

Some of the enzymes involved in pyrimidine nucleotide metabolism have been investigated in isoproterenol-stimulated salivary glands. Within the first $4 \mathrm{hr}$ after injection of isoproterenol there is an elevation of activity of the first two enzymes of the de novo pyrimidine pathway, carbamyl phosphate synthetase and aspartate transcarbamylase (123). This increased enzyme activity is found at a time when there is a maximum incorporation of orotic acid into RNA. The activity of uridine kinase is elevated at the same time that 
there is maximal incorporation of uridine into RNA. The importance of the elevated de novo pathway activity for the DNA biosynthesis was demonstrated by inhibiting orotidylate decarboxylase with 6 -azauridine. It was shown that thymidine incorporation into DNA was almost completely blocked with an amount of inhibitor adequate to completely block orotic acid incorporation into RNA, but insufficient to block uridine incorporation into RNA (123). These experiments indicate the importance of the de novo pyrimidine pathway as a source of precursors for RNA biosynthesis. This newly synthesized RNA is then required for subsequent biosynthesis of DNA.

In addition to its effect on de novo pyrimidine activity, isoproterenol also results in increased activities of thymidine kinase, thymidylate kinase, and DNA polymerase, although these enzymes attain maximum activities at approximately the same time that DNA biosynthesis takes place (9).

\section{INTESTINE}

Intestinal crypt cells show one of the highest rates of cellular proliferation found in mammalian tissues (67). After division in the crypt, cells migrate up the villus, during which time they develop the anatomic and biochemical characteristics of mature intestinal cells. It is possible to prepare serial slices of intestine, from crypt to villus, and subject those slices to histologic and biochemical study. The transformation of proliferating cells into differentiated cells can then be characterized by studying enzymes involved in pyrimidine biosynthesis and those involved in intestinal digestion. In the crypt, one finds high activity of enzymes from both de novo and reutilization pathways. Activity decreases along the villus to a minimum at the tip $(31,44,67,72,149)$. Conversely, enzymes typically associated with the differentiated intestinal cell increase from the crypt to the villus (44). A typical pattern is shown in Figure 6.

A compensatory increase in villus length occurs in patients who have undergone resection of a large part of the small bowel. Consequently, there is increased activity of functional enzymes such as lactase, sucrase, and maltase and an amelioration of the "short gut syndrome" (162). There is a definite increase in cellular proliferation and of cellular migration. Patients with celiac disease also seem to have increased intestinal proliferative activity, with an increase in activity of enzymes of the de novo pyrimidine pathway (31). Neoplastic lesions of the colon demonstrate an enzyme pattern limited normally to the proliferating cells of the crypts (149).

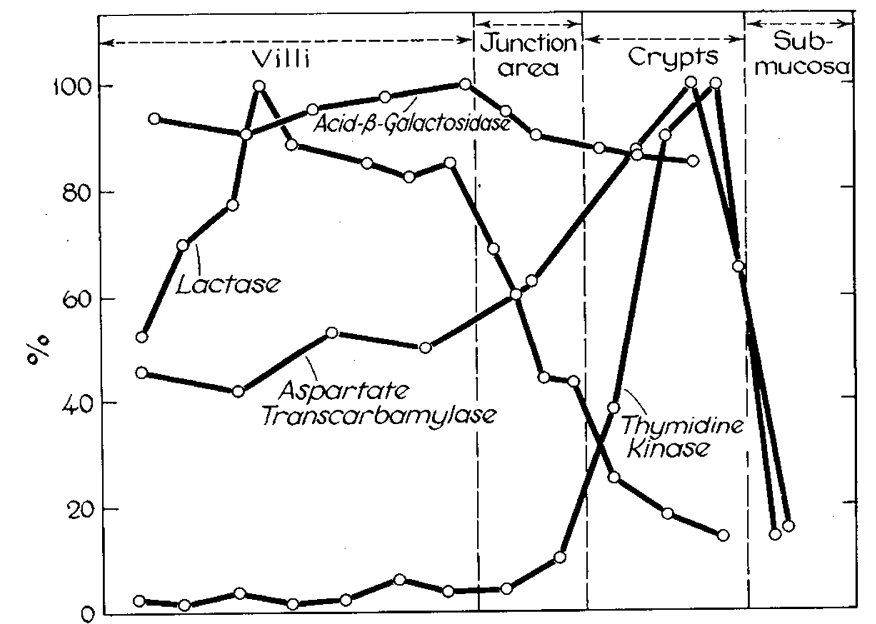

Fig. 6. Topographic distribution of enzymic activities in different regions of the rat jejunum. Enzyme assays were carried out on homogenates of tissue obtained by serial sectioning of the jejunum using a cryostat. This figure is reproduced from Fortin-Magana et al. (45) with permission of the authors and publisher. Copyright 1970 by the American Association for the Advancement of Science.

\section{REGENERATING LIVER}

After partial hepatectomy, there is a 24-hr lag before cell division occurs. A number of studies have attempted to elucidate the events that occur during this lag period. DNA biosynthesis occurs after some 12-39 hr, followed 6-8 hr later by mitosis. The activity of a number of enzymes rises with the increase in DNA biosynthesis. For example, thymidine kinase activity increases with DNA biosynthesis (17) and so does the activity of a species of DNA polymerase (113). After partial hepatectomy there is a rapid change in RNA metabolism. For example, incorporation of radioactive orotic acid into RNA reaches a peak at $5 \mathrm{hr}(50)$. This RNA biosynthesis is required for later cell division; inasmuch as DNA biosynthesis is prevented by $p$-fluorophenylalanine and actinomycin D (50). A feature of the RNA biosynthesis is that most of the newly formed RNA is found in the nucleus (50), as is the RNA made by kidney cortex cells after explantation (95), and by salivary glands after stimulation with isoproterenol $(6,123)$.

Despite the rapid changes in RNA synthesis which result from partial hepatectomy, aspartate transcarbamylase and dihydroorotase do not increase until $12-24 \mathrm{hr}$ after partial hepatectomy. Although orotate phosphoribosyl transferase and orotidylate decarboxylase activities increased within $2 \mathrm{hr}$ (18), Fausto (39) found that these enzymes are not rate-limiting for RNA biosynthesis in regenerating liver. Enzymes of the reutilization pathway of pyrimidine biosynthesis, such as uridine kinase, uridine phosphorylase, and deoxyuridine kinase also increased in activity after partial hepatectomy, but again, the stimulation was not observed until at least $24 \mathrm{hr}$ after surgery (133).

Thus, although many of the events preceding cell division in regenerating rat liver are known, the mechanism by which the pyrimidine nucleotides required for early RNA biosynthesis in this tissue are synthesized is still unclear. The time course of stimulation of enzymes studied does not correlate with the biosynthesis of these nucleotides. However, it should be noted that the enzyme likely to be rate-limiting for de novo pyrimidine biosynthesis, the glutamine-requiring carbamyl phosphate synthetase, has not been measured in regenerating liver.

\section{NEOPLASIA}

The transformation of cells into the neoplastic state is usually characterized by slow displacement in the molecular constitution. In general, rate-limiting enzymes show the greatest change, but all enzymes of nucleic acid biosynthesis tend to increase in activity while those involved in nucleic acid degradation tend to decrease (154). The ratio of opposing pathways characteristically changes ás the rate of tissue growth changes. For example, the ratio of thymidine incorporation to thymidine degradation increases with the growth rate of a series of hepatomas (42). Also, the decreased activity of the rate-limiting enzyme in thymidine degradation, dihydrouracil dehydrogenase, significantly correlates with growth rate in a series of hepatomas $(112,121)$.

Many enzymes involved in pyrimidine biosynthesis and degradation show the expected changes with different growth rates $(154,155)$. The activity of aspartate transcarbamylase correlates positively with the growth rate of normal tissues $(52,96,164)$, and with a series of neoplasms with varying growth rates $(21,25,112,142)$. The glutamine-requiring carbamyl phosphate synthetase is correlated with the mitotic index in normal tissue, and also with the growth rates of a series of tumors $(74,163)$. Similar relations have been reported for other enzymes in the synthetic pathway $(20,93$, $116,142)$. Conversely, enzymes in the degradative pathway show a negative correlation with growth rate $(21,42,121$, $138,155)$. 
There does not appear to be a single, unique enzyme which establishes the virulence of neoplastic growth. Instead, the gradual replacement of normal enzyme patterns by those characteristic of neoplasia correlates with the virulence of the tumor $(88,155)$. Knox (88) has emphasized that one must examine the pattern formed by a variety of cellular proteins in order to make meaningful comparisons between biologically distinct cells. Using a given reference tissue (e.g., adult liver for hepatomas) a number can be derived statistically which provides a quantitative measure of the difference between tissues. A gradual progression in pattern is observed: less differentiated tumors resembling each other more than the parent tissue; differentiated tumors resemble the parent tissue more than themselves (Fig. 7) (88). These models of proliferation provide examples of the two paradigms often utilized to define the biologic significance of pyrimidine biosynthesis. The first, or correlative paradigm, seeks to correlate biologic behavior with the molecular constitution of a cell. The possibility of identifying a key controlling enzyme in cancer cells led to the measurement of many enzyme activities in neoplasms of varying growth rates. However, virtually all enzymes studied have varied in a manner consistent with rate of tissue growth. Biologically it seems as valuable to emphasize the characteristic pattern of changes in pyrimidine metabolism seen in neoplasia, as to search for a unique factor which would explain the behavior of tumors.

The second, or developmental paradigm, emphasizes the temporal relation of genetic events which control the molecular machinery of dividing cells. Careful studies of the sequence of events which occur before cell division have begun to delineate the role of pyrimidine biosynthesis in cellular proliferation. In model mammalian systems, brief interference with protein synthesis or enzyme activity may prevent later cellular division.

\section{PHARMACOLOGIC PROPERTIES OF OROTIC ACID}

Studies of hereditary orotic aciduria have yielded important information concerning de novo pyrimidine biosynthesis (136) and control mechanisms of this pathway in higher organisms. Heriditary orotic aciduria is rare, although orotic aciduria is found commonly in patients receiving the anti-gout drug, allopurinol. Allopurinol is useful in treating gout because the

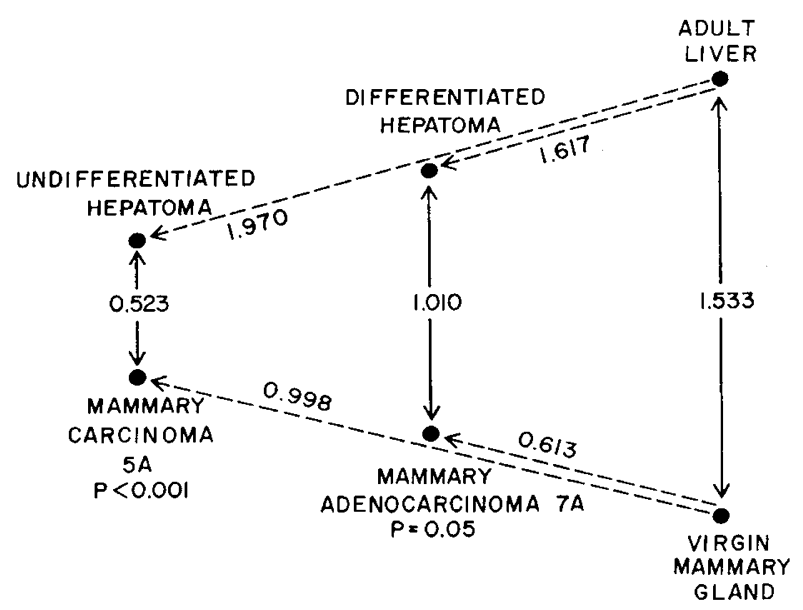

Fig. 7. Convergent patterns of undifferentiated tumors. The diagram shows the calculated distances between enzymic compositions (21 unselected components) of adult liver and virgin mammary gland, differentiated hepatoma and mammary adenocarcinoma $7 \mathrm{~A}$, and undifferentiated hepatoma and mammary carcinoma 5A. Distances between tumors of the two tissues are significantly less than between the parent tissues ( $P$ values shown). Redrawn from Knox (88) with permission of the author and publisher. drug decreases uric acid production by inhibiting xanthine oxidase (EC. 1.2.3.2), but it has been discovered recently that metabolites of the drug also inhibit de novo pyrimidine biosynthesis. Allopurinol causes an excretion of orotic acid and orotidine in a pattern similar to that found in a variant of hereditary orotic aciduria in which only orotidylate decarboxylase activity is low $(46,84,139)$. This observation suggests that allopurinol acts by inhibiting the decarboxylase $(46,48)$, probably through the conversion of allopurinol to oxypurinol (11).

Orotic acid may have a variety of clinical effects. The purported pharmacologic uses of orotic acid are numerous (30). Orotic acid has been claimed to increase the rate of regeneration after myocardial infarction; to counteract galactose-induced cataract and aid in the management of galactosemia; to nullify the diabetogenic action of alloxan; and to have an anti-inflammatory action in gouty arthritis similar to colchicine. The usefulness of allopurinol in gout could depend in part upon this last action of orotic acid.

Pyrimidine nucleotides are required as carriers of sugars and lipids. This may account for other pharmacologic effects of orotic acid. For example, orotic acid has significant protective effects on the liver. A low dose mixture of hepatotoxic substances (carbon tetrachloride, chlorophenothane, and 9,10-dimethyl-1,2-benzanthracene) causes pathologic liver changes when fed to rats for 4 months. The changes are prevented by the addition of orotic acid to the diet (115).

Small doses of $d$-galactosamine can induce a viral-like hepatitis. The rate-limiting step in the disposal of galactosamine involves the formation of UDP-galactosamine. The step appears to be limited not by the activity of the enzyme involved but by the availability of uridine nucleotides: The uridylate pool drops after the administration of galactosamine, and this decrease may be the cause of the hepatitis (37). The fall in the concentration of uridylate can be prevented by administration of orotic acid; hepatitis then does not develop.

The limited ability of neonates to conjugate bilirubin has been attributed generally to the limited activity of glucuronyl transferase (EC. 2.4.1.17). However, as in the case of galactosamine hepatitis, it is possible that UTP required for the formation of the substrate, UDP-glucuronic acid, is limiting, but the available experimental evidence is conflicting.

The involvement of orotic acid in hepatic metabolism is further corroborated by evidence that oral administration of orotic acid has a marked effect on lipid metabolism and at certain doses produces a severe fatty liver in rats. Standerfer and Handler (140) originally described the marked fatty infiltration caused by the addition of orotic acid to the diet of rats. The usual lipotropic agents such as folic acid, vitamin $\mathrm{B}_{12}$, methionine, and choline could not prevent the infiltration. Weanling rats fed a defined diet plus $1 \%$ orotic acid rapidly showed marked changes in hepatic nucleotides and fat content $(62,152)$. After only 10 days on the diet, uridine nucleotides were increased fourfold and fat content was increased over threefold. The liver content of adenine nucleotides was decreased by $50 \%$, and supplementation of the diet with $0.25 \%$ adenine sulfate completely prevented development of the fatty liver. The decrease in hepatic adenine nucleotide content was found to be caused by a stimulated purine turnover, with degradation predominating over synthesis (159). Allopurinol can restore the normal composition of the purine and pyrimidine pools and prevent the induction of fatty liver by orotic acid, apparently by inhibiting xanthine oxidase and orotidylate decarboxylase (159). The orotic acid does not appear to have any permanent harmful effects, as even after 2 years the fatty liver can be reversed within 7 days by stopping the orotic acid supplementation or by adding adenine to the diet (158). The fatty liver is caused by a blockade of triglyceride and betalipoprotein efflux from the liver. This phenomenon is limited to the liver; intestinal 
production and transport of triglycerides and betalipoproteins are unaffected $(49,158)$.

The normal dietary content of orotic acid in not known, but it is present in high concentration in the milk of ruminants. Orotic acid is synthesized by the mammary cell $(29,92)$, and is secreted in milk resulting in levels of about $8.3 \mathrm{mg} / 100 \mathrm{ml}$ $(61,111)$. In powdered milk the orotic acid level is about 130 $\mathrm{mg} / 100 \mathrm{~g} \mathrm{(111)}$, so that a powdered milk diet could reach $0.125 \%$ orotic acid. Minor effects on rat liver nucleotide pools and adenine deaminase can be seen with diets containing as little as $0.001 \%$ orotic acid $(100,101)$, and a diet with $0.2 \%$ doubled the liver fat content (140). The effects of orotic acid vary from species to species; although rats are susceptible to development of fatty liver, mice, chicks, and monkeys are not (151). Furthermore, although cow's milk has a high orotic acid content, calcium and lactose seem to protect against development of fatty liver (62). If these components are given to rats in the proportions found in milk, no fatty liver develops with administration of the orotic acid diet $(89,124)$.

Orotic acid appears to affect purine and lipoprotein metabolism in man in a manner qualitatively similar to that in the rat. Kelley et al (85) studied the effect of orotic acid fed to humans. Patients received $6 \mathrm{~g}$ orotic acid/24 hr for about 7 days, a dose comparable to that used in the studies with the rat. There was a prompt uricosuric effect and a decrease in de novo purine biosynthesis. The PRPP content of erythrocytes was decreased. Orotic acid also led to a modest decrease in plasma cholesterol, triglycerides, prebetalipoproteins, and betalipoproteins. These clinical effects are similar to those observed in patients receiving 6-azauridine, a drug which inhibits orotidylate decarboxylase and causes orotic aciduria and orotidinuria. Patients who receive the drug have a marked uricosuria, caused at least in part by the increased levels of orotic acid (38). These patients also show a pronounced decrease in serum cholesterol (24). It is clear from these limited studies that orotic acid has a variety of clinical effects in man. These effects may differ depending on whether orotic acid is supplied exogenously or whether the concentration in blood is increased by allopurinol, 6-azauridine, or hyperammonemia. In addition, developmental differences may cause differing effects in premature infants and adults.

\section{CONCLUSION}

Most of the enzymes which participate in pyrimidine biosynthesis have been studied extensively in vitro, but characteristics of in vivo control mechanisms of these pathways remain sketchy. Much emphasis has been given to the role of pyrimidine biosynthesis in systems which exhibit rapid cellular proliferation. These studies reveal that rapidly dividing cells demonstrate characteristic patterns of enzyme activities which are different from the patterns observed in nondividing systems. Nondividing tissues have usually differentiated to form specialized organs with particular functions. The pattern of enzyme activities also reflects this specialization.

More recently, the intimate involvement of pyrimidine compounds in other areas of cellular physiology, including carbohydrate, lipid, bilirubin, and membrane metabolism, has been recognized. There are suggestions that liver may play an important role in regulating the pyrimidine nucleosides in blood. Pathologic processes, inborn errors of metabolism, and iatrogenic intervention may alter the normal flux of pyrimidines through many metabolic pathways. These alterations are now being recognized clinically and should form the basis for rational pharmacologic intervention to produce desired changes in pyrimidine metabolism.

\section{REFERENCES AND NOTES}

1. Anderson, E. P., and Brockman, R. W.: Feedback inhibition of uridine kinase by cytidine triphosphate and uridine triphos- phate. Biochim. Biophys. Acta, 91: 380 (1964).

2. Appel, S. H.: Purification and kinetic properties of brain orotidine 5'-phosphate decarboxylase. J. Biol. Chem., 243: 3924 (1968).

3. Appel, S. H., and Pettis, P.: Regulation of brain orotidylic decarboxylase activity. Fed. Proc., 26: 292 (1967).

4. Babad, H., and Hassid, W. Z.: Soluble uridine diphosphate D-galactose: $D$-Glucose $\beta$-4-D-galactosyl transferase from bovine milk. J. Biol. Chem., 241: 2672 (1966).

5. Barka, T.: Stimulation of DNA synthesis by isoproterenol in the salivary gland. Exp. Cell Res. 39: 355 (1965).

6. Barka, T.: Stimulation of RNA synthesis in the salivary gland by isoproterenol. Exp. Cell Res., 41: 573 (1966).

7. Barka, T.: Induced cell proliferation: The effect of isoproterenol. Exp. Cell. Res., 37: 662 (1965).

8. Baserga, R.: Inhibition of stimulation of DNA synthesis by isoproterenol in submandibular glands of mice. Life Sci., 5: 2033 (1966).

9. Baserga, R.: Induction of DNA synthesis by a purified chemical compound. Fed. Proc, 29: 1443 (1970).

10. Baserga, R., and Heffler, S.: Stimulation of DNA synthesis by isoproterenol and its inhibition by actinomycin D. Exp. Cell Res., 46: 571 (1967).

11. Beardmore, T. D., and Kelley, W. N.: Mechanism of allopurinol mediated inhibition of pyrimidine biosynthesis. J. Lab. Clin. Med., 78: 696 (1971).

12. Becroft, D. M. O., and Phillips, L. I.: Hereditary orotic aciduria and megaloblastic anaemia: A second case, with response to uridine. Brit. Med. J., 1: 547 (1965).

13. Bendich, A., Getler, H., and Brown, G. B.: A synthesis of isotopic cytosine and a study of its metabolism in the rat. J. Biol. Chem., 177: 565 (1949).

14. Bertles, J. F., and Beck, W. S.: Biochemical aspects of reticulocy te maturation. I. Fate of the ribonucleic acid. J. Biol. Chem., 237: 3770 (1962)

15. Blair, D. G. R., and Potter, V. R.: Inhibition of orotidylic acid decarboxylase by uridine $5^{\prime}$-phosphate. J. Biol. Chem., 236 : 2503 (1961).

16. Blair, D. G. R., Stone, J. E., and Potter, V. R.: Formation of orotidine $5^{\prime}$-phosphate by enzymes from rat liver. J. Biol. Chem., 235: 2379 (1960).

17. Bollum, F. J., and Potter, V. R.: Nucleic acid metabolism in regenerating rat liver. VI. Soluble enzymes which convert thymidine to thymidine phosphates and DNA. Cancer Res., 19: $561(1959)$.

18. Bresnick, E.: Early changes in pyrimidine biosynthesis after partial hepatectomy. J. Biol. Chem., 240:2550 (1963).

19. Bresnick, E., and Hitchings, G. H.: Feedback control in Ehrlich ascites cells. Cancer Res., 21: 105 (1961).

20. Bresnick, E., Mainigi, K. D., Mayfield, E. D, Jr., and Morris, H. P.; Activities of enzymes of pyrimidine nucleotide synthesis in slowly growing kidney tumors. Cancer Res., 29: 1932 (1969).

21. Bresnick, E., Mayfield, E. D., Jr., Liebelt, A. G., and Liebelt, R. A.: Enzyme patterns in a group of transplantable mouse hepatomas of different growth rates. Cancer Res., 31: 743 (1971).

22. Bresnick, E., Thompson, V. B., Morris, H. P., and Liebelt, A. G.: Inhibition of thymidine kinase activity in liver and hepatomas by TTP and d-CTP. Biochem. Biophys. Res. Commun., 16: 278 (1964).

23. Brockman, R. W., and Anderson E. P.: Pyrimidine analogues. In: R. M. Hochster and J. H. Quastel: Metabolic inhibitors, Vol. 1, p. 239 (Academic Press, New York, 1963).

24. Buttoo, A. S., Israels, M. C. G., and Wilkinson, J. F.: Hypocholesterolaemia and orotic aciduria during treatment with 6-azauridine. Brit. Med. J., 1: 552 (1965).

25. Calva, E., Lowenstein, J. M., and Cohen, P. P.: Carbamyl phosphate-aspartate transcarbamylase activity in tumors. Cancer Res., 19: 101 (1959).

26. Camiener, G. W., and Smith, C. G.: Studies of the enzymatic deamination of cytosine arabinoside. I. Enzyme distribution and species specificity. Biochem. Pharmacol., 14: 1405 (1965).

27. Canellakis E. S.: Pyrimidine metabolism. I. Enzymatic pathways of uracil and thymine degradation. J. Biol. Chem., 221: 315 (1956).

28. Caravaca, J., and Grisolia, S.: Enzymatic decarbamylation of carbamyl $\beta$-alanine and carbamyl $\beta$-aminoisobutyric acid. J. Biol. Chem., 231: 357 (1958).

29. Chen, M. H., and Larson, B. L.: Pyrimidine synthesis pathway enzymes and orotic acid in bovine mammary tissue. J. Dairy Sci., 54: 842 (1971).

30. Cheng, C. C., and Roth, B.: Some pyrimidines of biological and medicinal interest. Part II. Progr. Med. Chem., 7: 285 (1970).

31. Clark, M. L., and Senior, J. R.: Small gut mucosal activities of pyrimidine precursor enzymes in celiac disease. Gastroenterology, 56:887 (1969).

32. Colombo, J. P.: Congenital disorders of the urea cycle and ammonia detoxication. Monogr. Paediat., $1: 1$ (1971). 
33. Creasey, W. A., and Handschumacher, R. E.: Purification and properties of orotidylate decarboxylases from yeast and rat liver. J. Biol. Chem., 236: 2058 (1961).

34. Creasey, W. A.: Studies on the metabolism of 5-iodo-2'-deoxycytidine in vitro. Purification of nucleoside deaminase from mouse kidney. J. Biol. Chem., 238: 1772 (1963).

35. Curci, M. R., and Donachie, W. D.: An attempt to find pyrimidine inhibitors of a mammalian aspartate carbamoyltransferase. Biochim. Biophys. Acta, 85: 338 (1964).

36. Davis, R. H.: Metabolite distribution in cells. Science, 178: 835 (1972).

37. Decker, K., Keppler, D., Rudigier, J., and Domschke, W.: Cell damage by trapping of biosynthetic intermediates. The role of uracil nucleotides in experimental hepatitis. Hoppe Seyler's $\mathrm{Z}$. Physiol. Chem., 352: 412 (1971).

38. Fallon, H. J., Frei, E., III, Block, J., and Seegmiller, J. E.: The uricosuria and orotic aciduria induced by 6 -azauridine. J. Clin. Invest., 40: 1906 (1961).

39. Fausto, N.: The control of RNA synthesis during liver regeneration. Orotidine $5^{\prime}$-phosphate pyrophosphorylase and decarboxylase activities in normal and regenerating liver. Biochim. Biophys. Acta, 182: 66 (1969).

40. Feinendegen, L. E., Bond, V. P., Cronkite, E. P., and Hughes, W. L.: RNA turnover in normal rat bone marrow. Ann. N. Y. Acad. Sci., 113: 727 (1964).

41. Feinendegen, L. E., Bond, V. P., and Hughes, W. L.: Physiological thymidine reutilization in rat bone marrow. Proc. Soc. Exp. Biol. Med., 122: 448 (1966).

42. Ferdinandus, J. A., Morris, H. P., and Weber, G.: Behavior of opposing pathways of thymidine utilization in differentiating, regenerating, and neoplastic liver. Cancer Res., 31: 550 (1971).

43. Forsdyke, D. R.: Studies of the incorporation of $(5-\mathrm{H}-3)$ uridine during activation and transformation of lymphocytes induced by phytohaemagglutinin. Dependence of the incorporation rate on uridine concentration. Biochem. J., 107: 197 (1968).

44. Forsdyke, D. R.: Application of the isotope-dilution principle to the analysis of factors affecting the incorporation of $\mathrm{H}-3$ uridine and $\mathrm{H}-3$ cytidine into cultured lymphocytes: Evaluation of pools. Biochem. J., 125: 721 (1971).

45. Fortin-Magana, R., Hurwitz, R., Herbst, J. J., and Kretchmer, N. Intestinal enzymes: Indicators of proliferation and differentiation in the jejunum. Science, 167: 1627 (1970).

46. Fox, R. M., and O'Sullivan, W. J.: Purine and pyrimidine biosynthesis. Allopurinol and inborn errors. Minn. Med., 54: 397 (1971).

47. Fox, R. M., O'Sullivan, W. J., and Firkin, B. G.: Orotic aciduria. Differing enzyme patterns. Amer. J. Med., 47: 332 (1969).

48. Fox, R. M., Wood, M. H., and O'Sullivan, W. J.: Studies on the coordinate activity and lability of orotidylate phosphoribosyltransferase and decarboxylase in human erythrocytes, and the effects of allopurinol. J. Clin, Invest. 50: 1050 (.1971).

49. Fredrickson, D. S., Gotto, A. M., and Levy, R. I.: Familial lipoprotein deficiency. In: J. B. Stanbury, J. B. Wyngaarden, and D. S. Fredrickson: The Metabolic Basis of Inherited Disease, Ed. 3, p. 493 (McGraw-Hill, New York, 1972).

50. Fujioka, M., Koga, M., and Lieberman, I.: Metabolism of ribonucleic acid after partial hepatectomy. J. Biol. Chem., 238: 3401 (1963).

51. Galanti, N., and Baserga, R.: Glycolipid synthesis in the early prereplicative phase of isoproterenol stimulated salivary glands of mice. J. Biol. Chem., 246: 6814 (1971).

52. Galofré, A., and Kretchmer, N.: Biosynthesis of pyrimidines by various organs of the chick during embryogenesis. Pediat. Res., 4: 55 (1970)

53. Geiger, A.: Correlation of brain metabolism and function by the use of a brain perfusion method in situ. Physiol. Rev., 38: 1 (1958).

54. Geiger, A., and Yamasaki, S.: Cy tidine and uridine requirement of the brain. J. Neurochem., 1: 93 (1956).

55. Goldstein, A. S., Hoogenraad, N. J., Johnson, J. D., Fukanaga, K., Swierczewski, E., Cann, H. M., and Sunshine, P.: Metabolic and genetic studies of a family with ornithine transcarbamylase deficiency. Pediat. Res., 8: 5 (1974)

56. Grisolia, S., and Cardoso, S. S.: The purification and properties of hydropyrimidine dehydrogenase. Biochim. Biophys. Acta, 25: 430 (1957)

57. Gurpide, E., Tseng, J., Escarcena, L., Fahning, M., Gibson, C., and Fehr, P.: Fetomaternal production and transfer of progesterone and uridine in sheep. Amer. J. Obstet. Gynec., 113:21 (1972).

58. Hager, S. E., and Jones, M. E.: Initial steps in pyrimidine synthesis in Ehrlich ascites carcinoma in vitro. I. Factors affecting the incorporation of ${ }^{14} \mathrm{C}$-bicarbonate into carbon 2 of the uracil ring of the acid soluble nucleotides. J. Biol. Chem., 240: $4556(1965)$

59. Hager, S. E., and Jones, M. E: Initial steps in pyrimidine synthesis in Ehrlich ascites carcinoma in vitro. II. The glutamine-dependent carbamyl phosphate synthetase. J. Biol. Chem., 242: 5667 (1967).

60. Hager, S. E., and Jones, M. E.: A glutamine-dependent enzyme for the synthesis of carbamyl phosphate for pyrimidine biosynthesis in fetal rat liver. J. Biol. Chem., 242: 5674 (1967). 61. Hallanger, L. E., Laakso, J. W., and Schultze, M. O.: Orotic acid in milk. J. Biol. Chem., 202: 83 (1953).

62. Handschumacher, R. E., Creasy, W. A., Jaffe, J. J., Pasternak, C. A., and Hankin, L.: Biochemical and nutritional studies on the induction of fatty livers by dietary orotic acid. Proc. Nat. Acad. Sci. U.S.A., 46: 178 (1960).

63. Hatfield, D., and Wyngaarden, J. B.: 3-Ribosylpurines. I. Synthesis of (3-ribosyluric acid) 5 '-phosphate and (3-ribosylxanthine) $5^{\prime}$-phosphate by a pyrimidine ribonucleotide pyrophosphorylase of beef erythrocytes. J. Biol. Chem., 239: 2580 (1964).

64. Hayashi, T. T., and Garvery, B. I.: Transplacental passage of nucleotides, nucleosides, and bases. Amer. J. Obstet. Gynecol. 102: 1154 (1968).

65. Hayashi, T. T., Shin, D. H., and Wiand, S.: Placental transfer of orotic acid, uridine, and UMP. I. Comparison of acid-soluble and acid-insoluble counts. Amer. J. Obstet. Gynecol. 102: 1144 (1968).

66. Heird, W. C., Nicholson, J. F., Driscoll, J. M., Schullinger, J. N., and Winters, R. W.: Hyperammonemia resulting from intravenous alimentation using a maxture of synthetic L-amino acids: A preliminary report. J. Pediat., 81: 162 (1972).

67. Herbst, J. J., Fortin-Magana, R., and Sunshine, P.: Relationship of pyrimidine biosynthetic enzymes to cellular proliferation in rat intestine during development. Gastroenterology, 59: 240 (1970).

68. Hers, H. G., De Wulf, H., Stahlmans, W., and Van Den Berghe, G.: The Control of glycogen synthesis in the liver. Advan. Enzyme Regul., 8: 171 (1969).

69. Hogans, A. F., Guroff, G., and Udenfriend, S.: Studies on the origin of pyrimidines for biosynthesis of neural RNA in the rat. J. Neurochem., 18: 1699 (1971).

70. Hoogenraad, N. J., and Lee, D. C.: Effect of uridine on de novo pyrimidine biosynthesis in rat hepatoma cells in culture. J. Biol. Chem., in press.

71. Hoogenraad, N. J., Levine, R. L., and Kretchmer, N.: Copurification of carbamoyl phosphate synthetase and aspartate transcarbamolase from mouse spleen. Biochem. Biophys. Res. Commun., 44: 981 (1971).

72. Imondi, A. R., Lipkin, M., and Balis, M. E.: Enzyme and template stability as regulatory mechanisms in differentiating intestinal epithelial cells. J. Biol. Chem., 245: 2194 (1970).

73. Ishii, K., and Green, H.: Lethality of adenosine for cultured mammalian cells by interference with pyrimidine biosynthesis. J. Cell Sci., 13: 429 (1973).

74. Ito, K., Nakanishi, S., Terada, M., and Tatibana, M.: Control of pyrimidine biosynthesis in mammalian tissues. II. Glutamine utilizing carbamoyl phosphate synthetase of various experimental tumors: distribution, purification, and characterization. Biochim. Biophys. Acta, 220: 477 (1970).

75. Ito, K., and Tatibana, M.: Operation of orotic acid pathways as the major source of pyrimidines in the hematopoietic mouse spleen. Biochem. Biophys. Res. Commun., 23: 672 (1966).

76. Ito, K., and Uchino, H.: Control of pyrimidine biosynthesis in human lymphocytes: Induction of glutamine utilizing carbamyl phosphate synthetase and operation of orotic acid pathway during blastogenesis. J. Biol. Chem., 246: 4060 (1971).

77. Jacobson, G. R., and Stark, G. R.: Aspartate transcarbamylases. In: P. D. Boyer: The Enzymes, Ed. 3, Vol. 9, p. 225 (Academic Press, New York, 1973).

78. Johnson, J. D., Albritton, W. L., and Sunshine, P.: Hyperammo nemia accompanying parenteral nutrition in newborn infants. $J$ Pediat., 81: 154 (1972)

79. Jones, M. E.: Vertebrate carbamyl phosphate synthetase I and II. In: B. Schmidt-Nielson: Urea and the Kidney, International Congress Series, No. 195, p. 35 (Excerpta Medica Foundation, Amsterdam, 1970).

80. Jones, M. E.: Regulation of pyrimidine and arginine biosynthesis in mammals. Advan. Enzyme Regul., 9: 19 (1970).

81. Jones, M. E.: Regulation of uridylic acid biosynthesis in eucaryotic cells. Curr. Top. Cell Regul., 6: 227 (1972).

82. Jones, M. E., Anderson, A. D., Anderson, C., and Hodes, S.: Citrulline synthesis in rat tissues. Arch. Biochem., 95: 499 (1961).

83. Kasbekar, D. K., Nagabhushanam, A., and Greenberg, D. M. Purification and properties of orotic acid decarboxylating enzymes from calf thymus. J. Biol. Chem., 239: 4245 (1964)

84. Kelley, W. N., and Beardmore, T. D.: Allopurinol: Alteration in pyrimidine metabolism in man. Science, 169: 388 (1970).

85. Kelley, W. N., Greene, M. L., Fox, I. H., Rosenbloom, F. M., Levy, R. I., and Seegmiller, J. E.: Effects of orotic acid on purine and lipoprotein metabolism in man. Metabolism, 19: 1025 (1970)

86. Kit, S.: Nucleotides and nucleic acids In: D. M. Greenberg: Metabolic Pathways, Ed. 3, Vol. 4, p. 69 (Academic Press, New York, 1970).

87. Klemperer, H. G., and Haynes, G. R.: Thymidine kinase in rat 
liver during development. Biochem. J., 108: 541 (1968).

88. Knox, W. E.: The protoplasmic patterns of tissues and tumors. Amer. Sci., 60: 480 (1972).

89. Kobata, A., Furuno, F., and Ziro, S.: The chemical components of milk which prevent the fatty liver induced by orotic acid. J. Biochem., 55: 92 (1964).

90. Krystal, G., and Webb, T. E.: Multiple forms of uridine kinase in normal and neoplastic rat liver. Biochem J., 124: 1943 (1971).

91. Larkin, L. H., and Stevens, A. R.: Foetal and maternal RNA labelled with H-3 cytidine. Nature New Biol., 235: 107 (1972).

92. Larson, B. L., and Hageman, E. C.: Ejection of orotic acid from the bovine mammary secretory cell. Fed. Proc., 29: 445 (1970).

93. Lea, M. A., Morris, H. P., and Weber, G: Comparative biochemistry of hepatomas. VI. Thymidine incorporation into DNA as a measure of hepatoma growth rate. Cancer Res., 26 : 465 (1966).

94. Levine, R. L., Hoogenraad, N. J., and Kretchmer, N.: Regulation of activity of carbamoyl phosphate synthetase from mouse spleen. Biochemistry, 10:3694 (1971).

95. Lieberman, I. Abrams, R., and Ove, P.: Changes in the metabolism of ribonucleic acid preceding the synthesis of deoxyribonucleic acid in mammalian cells cultured from the animal. J. Biol. Chem., 238: 2141 (1963).

96. Lowenstein, J. M., and Cohen, P. P.: Studies on the biosynthesis of carbamylaspartic acid. J. Biol. Chem., 220: 57 (1956).

97. Lucas, Z. J.: Pyrimidine nucleotide synthesis: Regulatory control during transformation of lymphocytes in vitro. Science, 156: 1237 (1967).

98. Lucas, Z. J.: Recent studies on the regulatory control of pyrimidine nucleotide synthesis in lymphocytes. In: W. $O$ Rieke: Proceedings of the Third Annual Leucocyte Culture Conference, p. 655 (Appleton-Century-Crofts, New York, 1969).

99. Malamud, D., and Baserga, R.: Pool size and specific activity of UTP in isoproterenol stimulated salivary glands. Biochim. Biophys. Acta, 195: 258 (1969).

100. Marchetti, M., Puddu, P., and Caldarera, C. M.: Liver acid soluble nucleotides in orotic acid fed rats. Biochim. Biophys. Acta, 61 . $826(1962)$

101. Marchetti, M., Puddu, P., and Caldarera, C. M.: Metabolic aspects of "orotic acid fatty liver." Nucleotide control mechanisms of lipid metabolism. Biochem. J., 92: (1964).

102. Martin, D. W., and Owen, N. T.: Repression and derepression of purine biosynthesis in mammalian hepatoma cells in culture. $J$. Biol. Chem., 247: 5477 (1972).

103. McMurray, W. C., and Magee, W. L.: Phospholipid metabolism. Annu. Rev. Biochem., 41: 129 (1972).

104. Michaelis, P., and Mandel, P: Etude du passage de quelques precurseurs de acides nucleiques du liquide cephaloarachidien dans le systeme nerveux central. C. R. Soc. Biol. (Paris), 158 : 1588 (1964).

105. Milner, J. A., and Visek, W. J.: Orotic aciduria and arginine deficiency. Nature New Biol., 245: 211 (1973).

106. Murray, A. W.: The biological significance of purine salvage. Annu. Rev. Biochem., 40: 811 (1971).

107. Natale, P. J., and Tremblay, G. C.: On the availability of intramitochondrial carbamoylphosphate for the extramito chondrial biosynthesis of pyrimidines. Biochem. Biophys. Res. Commun., 37: 512 (1969).

108. Nicholson, J. F.: Metabolism of ingested ammonium-N-15 by premature infants. Pediat. Res., 4: 398 (1970).

109. Nordlie, R. C., Lueck, J. D., Hanson, T. L., and Johns, P. J.: The nature of pH-discriminant differences in behavior of various phosphoanhydrides, mixed phosphate anhydrides, and phosphate esters as substrates and inhibitors with microsomal glucose 6-phosphatase. J. Biol. Chem., 246: 4807 (1971).

110. O'Donovan, G. A., and, Neuhard, J.: Pyrimidine metabolism in microorganisms. Bacteriol. Rev., 34: 278 (1970).

111. Okonkwo, P. O., and Kinsella, J. E.: Orotic acid in food milk powders. Amer. J. Clin. Nutr., 22: 532 (1969)

112. Ono, T., Blair, D. G. R., Potter, V. R., and Morris, H. P.: The comparative enzymology and cell origin of rat hepatomas. IV. Pyrimidine metabolism in minimal deviation tumors. Cancer Res., 23: 240 (1963)

113. Ove, P., Laszlo, J., Jenkins, M.D., and Morris, H. P.: Increased DNA polymerase activity in a series of rat hepatomas. Cancer Res., 29: 1557 (1969).

114. Parsons, D. F., and Subjeck, J. R.: The morphology of the polysaccharide coat of mammalian cells. Biochim. Biophys. Acta, 265: 85 (1972).

115. Pates, M. M., Tseitina, A. Y., Pomerantseva, I. I., Tunitskaya, T. A., Kurkina, V. S., and Turetskaya, I. M.: Protective action of orotic acid on the liver following exposure to low doses of toxic substances. Chem. Abstr., 70: 56116e (1969).

116. Pausch, J., Keppler, D., and Decker, K.: Activity and distribution of the enzymes of uridylate synthesis from orotate in animal tissues. Biochim. Biophys. Acta, 258: 395 (1972).

117. Plageman, P. G. W.: Nucleotide pools of Novikoff rat hepatoma cells growing in suspension culture. I. Kinetics of incorporation of nucleosides into nucleotide pools and pool sizes during growth cycle. J. Cell Physiol., 77: 213 (1971).

118. Plentl, A. A., and Schoenheimer, R.: Studies in the metabolism of purines and pyrimidines by means of isotopic nitrogen. J. Biol Chem., 153: 203 (1944).

119. Potter, V. R.: Metabolic products formed from thymidine. In: F. Stohlman, Jr.: The Kinetics of Cellular Proliferation, p. 104 (Grune and Stratton, New York, 1959).

120. Prager, M.D., Young J. E., and Atkins, I. C.: A study of the possible role of feedback inhibition of aspartate transcar bamylase in regulation of pyrimidine synthesis in human leukocy tes. J. Lab. Clin. Med., 70: 768 (1967)

121. Queener, S. F Morris, H. P., and Weber, G.: Dihydrouracil dehydrogenase activity in normal, differentiating, and regenerating liver and in hepatomas. Cancer Res., 31: 1004 (1971).

122. Rabinowitz, Y., Wong, P., and Wilhite, B.: Thymidine metabolizing enzymes of normal lymphocy tes cultured with phytohemag glutinin. In: O. R. McIntyre: Proceedings of the Fourth Annual Leucocyte Culture Conference, p. 81 (Appleton-Century-Crofts, New York, 1969).

123. Roux, J. M., Hoogenraad, N. J., and Kretchmer, N.: Biosyn thesis of pyrimidine nucleotides in mouse salivary glands stimulated with isoproterenol. J. Biol. Chem., 248: 1196 (1973).

124. Sarma, D. S., and Sidransky, H.: Studies on orotic acid fatty live in rats: Factors influencing the induction of fatty liver. J. Nutr. 98: 33 (1969).

125. Sasaki, T., and Baserga, R.: Cytoplasmic ribonucleic acid synthesis in the prereplicative phase of isoproterenol induced cell proliferation. Exp. Mol. Pathol., 13: 25 (1970).

126. Sasaki, T., Litwack, G., and Baserga, R.: Protein synthesis in the early prereplicative phase of isoproterenol stimulated synthesis of deoxyribonucleic acid. J. Biol. Chem., 244: 4831 (1969)

127. Schneider, W. C., and Greco, A. E.: Incorporation of pyrimidine deoxyribonucleosides into liver lipids and other components. Biochim. Biophys. Acta, 228: 610 (1971).

128. Shambaugh, G. E., III, Metzger, B. E., and Freinkel, N.: Glutamine dependent carbamyl phosphate synthetase in placenta and fetal structures of the rat. Biochem. Biophys. Res. Commun., 42: 155 (1971).

129. Shih, V. E, and Efron, M. L.: Urea cycle disorders. In: J. B. Stanbury, J. B. Wyngaarden, and D. S. Fredrickson: The Metabolic Basis of Inherited Disease, Ed. 3, p. 370 (McGrawHill, New York, 1972).

130. Shoaf, W. T., and Jones, M. E.: Initial steps in pyrimidine synthesis in Ehrlich ascites carcinoma. Biochem. Biophys. Res. Commun., 45: 796 (1971).

131. Shoaf, W. T., and Jones, M. E.: Enzyme complexes of the pyrimidine pathway in Ehrlich ascites tumor cells. Fed. Proc., 31: 473 (1972)

132. Shoaf, W. T., and Jones, M. E.: Uridylic acid synthesis in Ehrlich ascites carcinoma Properties, subcellular distribution, and nature of enzyme complexes of the six biosynthetic enzymes. Biochemistry, 12: 4039 (1973).

133. Sköld, O.: Enzymes of uracil metabolism in tissues with different growth characteristics. Biochim. Biophys. Acta, 44: 1 (1960).

134. Sköld 0 . Uridine kinase from Ehrlich ascites tumor: Purification and properties. J. Biol. Chem., 235: 3273 (1960).

135. Sköld, O.: Studies on resistance against 5-fluorouracil. IV. Evidence for an altered uridine kinase in resistant cells. Biochim. Biophys. Acta, 76: 160 (1963)

136. Smith, L. H., Jr., Huguley, C. M., Jr., and Bain, J. A.: Hereditary orotic aciduria. In: J. B. Stanbury, J. B. Wyngaarden, and D. S. Frederickson: The Metabolic Basis of Inherited Disease, Ed. 3, p. 1003 (McGraw-Hill, New York, 1972).

137. Sneider, T.W., and Potter, V. R.: Deoxycytidylate deaminase and related enzymes of thymidine triphosphate metabolism in hepatomas and precancerous rat liver. Advan. Enzyme Regul., 7: 375 (1968).

138. Sneider, T. W., Potter, V. R., and Morris, H. P.: Enzymes of thymidine triphosphate synthesis in selected Morris hepatomas. Cancer Res., 29: 40 (1969).

139. Soutter, G. B., Yu, J. S., Lovric, A., and Stapleton, T.: Hereditary orotic aciduria. Aust. Paediat. J., 6: 47 (1970).

140. Standerfer, S. B., and Handler, P.: Fatty liver induced by orotic acid feeding. Proc. Soc. Exp. Biol. Med., 90: 270 (1955)

141. Stein, G., and Baserga, R.: The synthesis of acidic nuclear proteins in the prereplicative phase of the isoproterenol stimulated salivary gland. J. Biol. Chem., 245: 6097 (1970).

142. Sweeney, M. J., Hoffman, D. H., and Poore, G. A.: Enzymes in pyrimidine biosynthesis. Advan. Enzyme Regul., 9: 51 (1970).

143. Tatibana, M., and Ito, K.: Carbamyl phosphate synthetase of the hematopoietic mouse spleen and the control of pyrimidine biosynthesis. Biochem. Biophys. Res. Commun., 26: 221 (1967).

144. Tatibana, M., and Ito, K.: Control of pyrimidine biosynthesis in mammalian tissues. I. Partial purification and characterization of glutamine-utilizing carbamyl phosphate synthetase of mouse spleen and its tissue distribution. J. Biol. Chem, 244: 5403 (1969). 
145. Tatibana, M., and Shigesada, K.: Activation by 5-phosphoribosylpyrophosphate of glutamine dependent carbamyl phosphate synthetase from mouse spleen. Biochem. Biophys. Res. Com mun., 46: 491 (1972).

146. Tatibana, M., and Shigesada, K.: Control of pyrimidine biosynthesis in mammalian tissues. IV. Requirements of a quantitative assay of glutamine dependent carbamyl phosphate synthetase and effect of magnesium as essential activator. J. Biochem., 72: 537 (1972).

147. Tatibana, M., and Shigesada, K.: Control of pryimidine biosynthesis in mammalian tissues. V. Regulation of glutamine dependent carbamyl phosphate synthetase: Activation by 5-phosphoribosyl 1 -pyrophosphate and inhibition by UTP. J. Biochem., 72 : 549 (1972).

148. Tomchick, R., Saslaw, L. D., and Waravdekar, V. S.: Mouse kidney cytidine deaminase: Purification and properties. J. Biol. Chem., 243: 2534 (1968).

149. Troncale, F., Hertz, R., and Lipkin, M.: Nucleic acid metabolism in proliferating and differentiating colonic cells of $m$ an and in neoplastic lesions of the colon. Cancer Res., 31: 463 (1971).

150. Tseng, J., Barelkovski, J., and Gurpide, E.: Rates of formation of blood-borne uridine and cytidine in dogs. Amer. J. Physiol., 221: 869 (1971).

151. Valli, E. A., Sarma, D. S. R., and Sarma, P. S.: Species specificity in orotic acid induced fatty liver. Indian J. Biochem., 5: 120 (1968).

152. Von Euler, L. H., Rubin, R. J., and Handschumacher, R. E.: Fatty livers induced by orotic acid. II. Changes in nucleotide metabolism. J. Biol. Chem., 238: 2464 (1963).

153. Wallach, D. P.: Grisolia, S.: The purification and properties of hydropyrimidine hydrase. J. Biol. Chem., 226: 277 (1957).

154. Weber, G., and Lea, M. A.: The molecular correlation concept. An experimental and conceptual method in cancer research. In: $\mathrm{H}$. Busch: Methods in Cancer Research, Vol. 2, p. 523 (Academic Press, New York, 1967)

155. Weber, G., Queener, S. F., and Ferdinandus, J. A.: Control of gene expression in carbohydrate, pyrimidine, and DNA metabolism. Advan. Enzyme Regul., 9: 63 (1970).

156. Weichsel, M. E., Jr., Hoogenraad, N. J., Levine, R. L., and Kretchmer, N.: Pyrimidine biosynthesis during development of rat cerebellum. Pediat. Res., 6:682 (1972).

157. Weissman, S. M., Lewis, M., and Karon, M.: The metabolism of

Copyright (c) 1974 International Pediatric Research Foundation, Inc. isotopically labeled uracil and uridine in man. Metabolism, 12 60 (1963).

158. Windmueller, H. G., Levy, R. I., and Spaeth, A. E.: Selective inhibition of hepatic but not intestinal beta-lipoprotein production and triglyceride transport in rats given orotic acid. Advan. Exp. Med. Biol., 4: 365 (1969).

159. Windmueller, H. G., and Spaeth, A. E.: Stimulation of hepatic purine biosynthesis by orotic acid. J. Biol. Chem., 240: 4398 (1965).

160. Windmueller, H. G., and Von Euler, L. H.: Prevention of orotic acid induced fatty liver with allopurinol. Proc. Soc. Exp. Biol. Med., 136: 98 (1971).

161. Winzler, R. J.: Carbohydrate in cell surfaces. Int. Rev. Cytol., 29: 77 (1970).

162. Wright, H. K., and Tilson, M.D.: The short gut syndrome: Pathophysiology and treatment. Curr. Probl. Surg., June: 1 (1971).

163. Yip, M. C., and Knox, W. E.: Glutamine-dependent carbamyl phosphate synthetase: Properties and distribution in normal and neoplastic rat tissues. J. Biol. Chem., 245: 2199 (1970).

164. Young, J. E., Prager, M.D., and Atkins, I. C.: Comparative activities of aspartate transcarbamylase in various tissues of the rat. Proc. Soc. Exp. Biol. Med., 125: 860 (1967).

165. Work from this laboratory was supported in part by grants from the National Foundation-March of Dimes, the Lockheed Employee's Bucks-of-the-Month Club, and the National Institutes of Health HD-00391, HD-02147, and Training Grant No. HD-00049, from the United States Public Health Service. Computer support was provided by the Advanced Computer for Medical Research (ACME) Facility of Stanford University Medical Center, with support from the Biotechnology Resources Branch of the National Institutes of Health under Grant No. RR-00311.

166. Dr. R. L. Levine was a Prédoctoral Fellow of the Medical Scientist Training Program, under National Institutes of Health Grant No. GM-1922.

167. Requests for reprints should be addressed to: N. Kretchmer, M.D., Ph.D., Division of Developmental Biology, Department of Pediatrics, Stanford University Medical Center, Stanford, Calif. 94305 (USA).

168. Accepted for publication March 18, 1974.

Printed in U.S.A. 